\title{
Aerobic and resistance exercise improves Reynolds risk score in overweight or obese breast cancer survivors
}

Kyuwan Lee ${ }^{1}$, Nathalie Sami ${ }^{2}$, Debu Tripathy ${ }^{3}$, Wendy Demark-Wahnefried ${ }^{4}$, Mary K. Norris ${ }^{5}$, Kerry S. Courneya ${ }^{6}$ and Christina M. Dieli-Conwright ${ }^{5^{*}}$ (D)

\begin{abstract}
Background: Breast cancer survivors have double the risk of mortality from cardiovascular disease than agematched women without a cancer history. Reynolds risk score (RRS) is a validated algorithm for the assessment of cardiovascular disease risk. This secondary analysis sought to examine the effects of a 16-week aerobic and resistance exercise intervention on RRS in overweight or obese breast cancer survivors.

Methods and results: One hundred overweight or obese $\left(\mathrm{BMl}>25 \mathrm{~kg} / \mathrm{m}^{2}\right)$ breast cancer survivors were randomized to exercise or usual care. The exercise group underwent aerobic and resistance exercise sessions for 16 weeks. RRS was calculated using a validated equation. Group differences in mean change for RRS were evaluated using repeated-measures analyses of variance. Post-intervention, RRS was significantly reduced ( $7.9 \pm 0.9 \%$ to $1.0 \pm 0.5 \% ; p<0.001)$ in the exercise group compared to a significant increase $(9.0 \pm 0.8 \%$ to $11.6 \pm 1.2 \% ; p=0.002 \%)$ in the usual care group $(p<0.01)$. RRS was significantly reduced in exercise vs usual care (between group difference, -10.6 ; $95 \% \mathrm{Cl},-16.3$ to $-7.4 ; p<0.001$ ).
\end{abstract}

Conclusion: A 16-week aerobic and resistance exercise intervention is an effective approach to reduce the risk of cardiovascular disease in breast cancer survivors. Exercise during cancer survivorship should be considered to reduce the risk for cardiovascular disease risk in overweight women breast cancer survivors.

Trial registration: ClinicalTrials.gov: NCT01140282. Registered 9 June 2010

Keywords: Exercise, Cardiovascular disease, Cancer

\section{Background}

Breast cancer survivors have approximately double the risk of mortality from cardiovascular disease than agematched women without a cancer history [1]. Framingham risk score (FRS) has been used to estimate the 10year risk of cardiovascular disease in breast cancer

\footnotetext{
* Correspondence: ChristinaM_Dieli-Conwright@DFCl.Harvard.edu For all authors: The authors take responsibility for all aspects of the reliability and freedom from bias of the data presented and their discussed interpretation.

${ }^{5}$ Division of Population Sciences, Department of Medical Oncology, Dana-Farber Cancer Institute, Harvard Medical School, 375 Longwood Avenue, Boston, MA 02215, USA

Full list of author information is available at the end of the article
}

survivors [2]. However, the accuracy of FRS has been limited due to the absence of inflammatory markers, glycated hemoglobin (HbA1c) and family history of cardiovascular disease in the prediction algorithm [3]. Reynolds risk score (RRS) was developed in 2007 for use in women and men for the assessment of cardiovascular disease which incorporates high sensitivity C-Reactive Protein (hsCRP), HbA1c, and parental history of myocardial infarction, along with traditional biomarkers including total cholesterol (TC), high-density lipoprotein cholesterol (HDL-C), systolic blood pressure (SBP), and presence of diabetes. The algorithm was validated in a

(c) The Author(s). 2020 Open Access This article is licensed under a Creative Commons Attribution 4.0 International License, which permits use, sharing, adaptation, distribution and reproduction in any medium or format, as long as you give appropriate credit to the original author(s) and the source, provide a link to the Creative Commons licence, and indicate if changes were made. The images or other third party material in this article are included in the article's Creative Commons licence, unless indicated otherwise in a credit line to the material. If material is not included in the article's Creative Commons licence and your intended use is not permitted by statutory regulation or exceeds the permitted use, you will need to obtain permission directly from the copyright holder. To view a copy of this licence, visit http://creativecommons.org/licenses/by/4.0/. The Creative Commons Public Domain Dedication waiver (http://creativecommons.org/publicdomain/zero/1.0/) applies to the data made available in this article, unless otherwise stated in a credit line to the data. 
large multi-ethnic Women's Health Initiative Observational Cohort [4].

We previously reported significant improvements in FRS following a 16-week resistance and aerobic exercise intervention resulting from the improvements in SBP, HDL-C, and TC in overweight or obese women with breast cancer [5]. Here, we report the findings of an unplanned secondary analysis of a randomized controlled trial comparing a progressive aerobic and resistance exercise intervention versus usual care on baseline to 4month changes in overweight or obese women with breast cancer. Detailed methods [6], and primary outcomes related to metabolic syndrome were published previously [7]. We hypothesized that a 16-week progressive aerobic and resistance exercise intervention would reduce RRS in sedentary, overweight or obese patients with early stage breast cancer compared to usual care.

\section{Methods}

One hundred eligible women with breast cancer were recruited between August 1, 2012 and December 31, 2016. The protocol and informed consent were approved by the institutional review board (HS-12-00141) and participants gave written informed consent. Participants were $<6$ months post-treatment for stage I-III female breast cancer and were nonsmokers, sedentary $(<60 \mathrm{~min}$ of structured exercise/week), with body mass index (BMI) $\geq 25.0 \mathrm{~kg} / \mathrm{m}^{2}$ or body fat $>30 \%$ and waist circumference $>88 \mathrm{~cm}$.

RRS was calculated using gender specific validated methodology [4], at baseline and week 17. The following data were collected in order to calculate RRS: age, SBP, hsCRP, TC, HDL-C, HbA1c, current smoking status, and parental history of myocardial infarction. Due to the primary study design, current smokers were ineligible and therefore smoking status did not vary by patient. Age and parental history of myocardial infarction were abstracted from medical records. SBP was measured three times using the arm contralateral to the affected breast with an automated sphygmomanometer after five minutes of quiet sitting, (Welch Allyn, Skaneateles Falls, New York). Plasma and serum biomarkers were analyzed from fasting $(\geq 12 \mathrm{~h})$ blood samples that were stored at $80^{\circ} \mathrm{C}$ until batch analysis at study completion. The following RRS equation was used to calculate 10-year cardiovascular disease risk $(\%)=[1-0.98634(\exp [\mathrm{B}-$ $22.325])] \times 100 \%$ where $\mathrm{B}=0.0799 \times$ age $+3.137 \times$ natural logarithm $(\mathrm{SBP})+0.180 \times$ natural logarithm (high-sensitivity C-reactive protein) $+1.382 \times$ natural logarithm (TC) $-1.172 \times$ natural logarithm $(\mathrm{HDL}-\mathrm{C})+0.134 \times$ HbA1c (\%) (if diabetic) +0.818 (if current smoker) + 0.438 (if family history of premature myocardial infarction).
The 16-week exercise intervention was designed based on American College of Sports Medicine/American Cancer Society exercise guidelines for cancer survivors ( $\geq 150$ min of aerobic exercise and $2-3$ days of resistance exercise training/week) [8, 9]. Women participated in thrice weekly supervised one-on-one exercise sessions for 16 weeks. Days one and three endorsed resistance and aerobic exercise of approximately $80 \mathrm{~min}$. Day two included approximately $50 \mathrm{~min}$ of aerobic exercise. Aerobic exercise included treadmill walking, rowing machine, or stationary cycling. Heart rate was monitored throughout the aerobic exercise sessions to maintain the heart rate at 65 to $80 \%$ maximum heart rate. Resistance exercise sessions included leg press, leg flexion, leg extension, chest press, seated row, bicep curls, and triceps pulldowns. Initial resistance was set at $80 \%$ of 1 repetition maximum (1-RM) for lower body exercises and 60\% 1-RM for upper body exercises which were determined during baseline testing.

The sample size was based on changes in insulin with a 16-week exercise intervention among survivors of breast cancer. Enrollment of 100 women provided $80 \%$ statistical power $(p<0.05)$ to detect a $2.6-\mathrm{mU} / \mathrm{mL}(\mathrm{SD}=$ $4.0 \mathrm{mU} / \mathrm{mL}$ ) difference in mean insulin levels, assuming $20 \%$ dropout using a two-group $t$ test. Within-group and between-group differences in mean change for individual outcomes measured at 16 weeks were evaluated using general linear models repeated-measures analyses of variance and mixed model repeated-measures analysis, respectively. A priori covariates with potential associations with the outcome of interest (e.g., type of treatment [chemotherapy, radiation, or both], surgery-type, medication use [e.g., anti-hypertensives and hyperglycemia medications], BMI, caloric intake, diet quality, and macronutrient distribution) were explored in models, but none modified the results. Analyses were performed using SAS (SAS/STAT User's Guide, Version 9.4; SAS Institute, Cary, NC).

\section{Results}

Baseline characteristics are reported elsewhere [7], and there were no significant differences between the two groups. The women were Hispanic white $(55 \%)$ or nonHispanic (45\%) and on average, $53.5 \pm 10.4$ years old, $6.2 \pm 2.1$ months from diagnosis, with a BMI of $33.5 \pm$ $5.5 \mathrm{~kg} / \mathrm{m}^{2}$. Women who underwent chemotherapy and were potentially exposed to cardiotoxic therapies and represented $10 \%$ of the total sample. Those with left sided breast irradiation included 22 participants in the exercise group and 19 in the control group. No difference in results were found when stratified by this variable. Exercise intervention compliance was 95\%, a strong indicator that the exercise program was well tolerated. No adverse events occurred during the study. Following 
the 16-week intervention period, RRS was significantly reduced $(7.9 \pm 0.9 \%$ to $1.0 \pm 0.5 \% ; p<0.001)$ in the exercise group compared to the usual care group (Table 1). The significant reduction of RRS resulted from improvements in hsCRP $(3.4 \pm 0.6$ to $2.3 \pm 0.3 \mathrm{mg} / \mathrm{L} ; \mathrm{p}<0.001)$, HbA1c $(7.5 \pm 0.9$ to $2.9 \pm 0.2 \% ; \mathrm{p}<0.001)$, and previously reported values of SBP $(132.9 \pm 13.0$ to $120.7 \pm 9.5$ mmHg; p < 0.001), HDL-C $(43.1 \pm 6.6$ to $64.7 \pm 7.8 \mathrm{mg} /$ $\mathrm{dL})$ and TC $(196.5 \pm 53.4$ to $157.5 \pm 37.1 \mathrm{mg} / \mathrm{dL})$ [7] in the exercise group compared to the usual care group. In contrast, there was a significant increase in RRS $(9.0 \pm$ 0.8 to $11.6 \pm 1.2 \%$; $p=0.002)$ in the usual care group, resulting from slight, non-statistically significant increases in HbA1c $(7.5 \pm 0.8$ to $7.9 \pm 0.8 ; p=0.28)$, and previously reported values of TC $(194.4 \pm 48.9$ to $210.4 \pm 52.2 ; p=0.31)$, HDL-C $(41.0 \pm 4.3$ to $39.9 \pm 4.0$; $p=0.45), \operatorname{SBP}(133.7 \pm 9.7$ to $135.9 \pm 9.8 ; p=0.22)$, hsCRP (3.7 \pm 0.3 to $4.2 \pm 0.4 ; p=0.54)$ [7].

\section{Discussion}

This secondary and unplanned analysis of supervised 16week aerobic and resistance exercise intervention originally designed to improve metabolic syndrome, also led to clinically significant reductions in RRS for 10-year risk of developing cardiovascular disease among sedentary, overweight/obese patients with early stage breast cancer. While FRS includes age, SBP, smoking, diabetes, and total and HDL-C in a prediction algorithm, cardiovascular disease risk is also associated with family history, markers of inflammation such as hsCRP, and HbAlc among individuals without known cardiovascular diseases [10-12]. Given that an overweight and obese status at the time of diagnosis or weight gain after diagnosis of breast cancer is associated with elevated levels of inflammatory markers (i.e. hsCRP) [13], and metabolic disturbances (i.e. HbA1C) [14], RRS may be useful, and perhaps a more indicative measure to estimate the future

Table 1 Comparison of Reynolds risk score variables between exercise and usual care groups

\begin{tabular}{|c|c|c|c|c|c|}
\hline \multirow[t]{2}{*}{ Variable } & \multirow{2}{*}{$\begin{array}{l}\text { Baseline, mean (SD) } \\
\text { Mean (SD) }\end{array}$} & \multicolumn{2}{|l|}{ Post-intervention } & \multicolumn{2}{|c|}{ Between Group Difference Post intervention } \\
\hline & & Mean (SD) & $P *$ & Mean $(95 \% \mathrm{Cl})$ & $P^{+}$ \\
\hline \multicolumn{6}{|l|}{ Age (yrs) } \\
\hline Exercise & $52.8(10.6) ;(n=50)$ & $52.8(10.6) ;(n=48)$ & - & - & - \\
\hline Usual Care & $53.6(10.1) ;(n=50)$ & $53.6(10.1) ;(n=45)$ & & & \\
\hline \multicolumn{6}{|c|}{ Systolic blood pressure $(\mathrm{mmHg})$} \\
\hline Exercise & $132.9(13.0)$ & $120.7(9.5)$ & $<0.001^{*}$ & $-13.7(-16.5$ to -8.7$)$ & $<0.001^{\dagger}$ \\
\hline Usual Care & $133.7(9.7)$ & $135.9(9.8)$ & 0.22 & & \\
\hline \multicolumn{6}{|l|}{ hsCRP (mg/L) } \\
\hline Exercise & $3.4(0.6)$ & $2.3(0.3)$ & $<0.001^{*}$ & $-1.9(-5.2$ to -0.6$)$ & $<0.001^{\dagger}$ \\
\hline Usual Care & $3.7(0.3)$ & $4.2(0.4)$ & 0.54 & & \\
\hline \multicolumn{6}{|c|}{ Total Cholesterol (mg/dL) } \\
\hline Exercise & $196.5(53.4)$ & $157.5(37.1)$ & $<0.001^{*}$ & $-52.9(-75.0$ to -43.0$)$ & $<0.001^{\dagger}$ \\
\hline Usual Care & $194.4(48.9)$ & $210.4(52.2)$ & 0.31 & & \\
\hline \multicolumn{6}{|c|}{ HDL-C (mg/dL) } \\
\hline Exercise & $43.1(6.6)$ & $64.7(7.8)$ & $<0.001^{*}$ & 24.4 (17.9 to 27.9$)$ & $<0.001^{\dagger}$ \\
\hline Usual Care & $41.0(4.3)$ & $39.9(4.0)$ & 0.45 & & \\
\hline \multicolumn{6}{|c|}{ Hemoglobin A1C (\%) } \\
\hline Exercise & $7.5(0.9)$ & $2.9(0.2)$ & $<0.001^{*}$ & $-4.6(-11.2$ to -1.6$)$ & $<0.001^{\dagger}$ \\
\hline Usual Care & $7.5(0.8)$ & $7.9(0.8)$ & 0.28 & & \\
\hline \multicolumn{6}{|c|}{ Parent with MI before age 60 years, n (\%) } \\
\hline Exercise & $40(80)$ & $40(80)$ & - & - & - \\
\hline Usual Care & $42(84)$ & $42(84)$ & & & \\
\hline \multicolumn{6}{|c|}{ 10-year Risk RRS (\%) } \\
\hline Exercise & $7.9(0.9)$ & $1.0(0.5)$ & $<0.001^{*}$ & $-10.6(-16.3$ to -7.4$)$ & $<0.001^{\dagger}$ \\
\hline Usual Care & $9.0(0.8)$ & $11.6(1.2)$ & $0.002^{*}$ & & \\
\hline
\end{tabular}

*P value for repeated-measures ANOVA comparing changes in the exercise group from baseline to post-intervention, and in the usual care group from baseline to post-intervention

' $P$ value for mixed model analysis comparing changes between the exercise and usual care group from baseline to post-intervention

Age and parent history of MI before 60 years calculated as unchanged during the 16-week intervention period 
risk of developing cardiovascular disease in breast cancer survivors.

This is the first randomized clinical trial of exercise training in women with early stage breast cancer to demonstrate the benefits of an exercise intervention on RRS in any clinical populations. While we previously reported aerobic and resistance exercise improves FRS [5], our findings were limited because inflammatory and diabetes-related status were not accounted for in the FRS. Cardiovascular disease risk assessed by RRS may address these limitations, and RRS was significantly reduced by our intervention. As HbA1c and hsCRP are associated with obesity $[10,11]$, and our overweight/obese participants significantly lost body fat following 16 weeks [7], the large effects of exercise may have occurred by regulating adipose tissue yet further mechanisms need to be identified at the tissue level. In addition, our study was limited to overweight and obese women thus future studies should include regular weight women $(\mathrm{BMI}<25)$ to determine whether RRS would have a similar decrease in non-overweight/obese breast cancer survivors. Lastly, RRS increased in the usual care group following the 16week study period demonstrating increased risk of future cardiovascular disease yet no change in FRS was previously found, possibly due to the improved sensitivity of RRS algorithm as reported by Cook et al. (2012) [15].

In conclusion, a 16-week resistance and aerobic exercise intervention decreased the 10-year risk of developing cardiovascular disease assessed by RRS by decreasing hsCRP, HbA1c, SBP, TC and increasing HDL-C. Overweight/obese women breast cancer survivors may consider performing regular aerobic and resistance exercise to reduce future cardiovascular disease during cancer survivorship.

\section{Abbreviations}

RRS: Reynolds risk score; BMI: Body mass index; FRS: Framingham risk score; HbA1c: Glycated hemoglobin; hsCRP: C-reactive protein; TC: total cholesterol; HDL-C: High-density lipoprotein cholesterol; SBP: Systolic Blood Pressure; 1RM: 1-repetition maximum; SD: Standard deviation

\section{Acknowledgements}

We acknowledge the Clinical Investigations Support Office of the Norris Comprehensive Cancer Center for their regulatory support of this investigation and the extraordinary generosity of our study participants.

\section{Authors' contributions}

Conceptualization (WDW, KC, CDC); Methodology (WDW, KC, CDC); Writing Original Draft (KL, NS, DT, WDW, KC, CDC); Review \& Editing (All authors); Resources (CDC); Supervision (CDC). All authors have read and approved the manuscript.

\section{Funding}

This project was supported by grant K07CA160718 from the National Cancer Institute, UL1TR001855 and UL1TR000130 from the National Center for Advancing Translational Science (NCATS) of the U.S. National Institutes of Health.

\section{Availability of data and materials}

The datasets used and/or analyzed during the current study are available from the corresponding author on reasonable request.

\section{Ethics approval and consent to participate}

The protocol and informed consent were approved by the University of Southern California Institutional Review Board (HS-1500227); ClinicalTrials.gov: NCT01140282; date of registration: June 9th, 2010.

\section{Consent for publication}

Not applicable.

\section{Competing interests}

The authors declare that they have no competing interests.

\section{Author details}

'Department of Population Sciences, Beckman Research Institute, City of Hope, Duarte, CA 91010, USA. ${ }^{2}$ Department of Medicine, Keck School of Medicine, University of Southern California, Los Angeles, CA 90033, USA. ${ }^{3}$ Department of Breast Medical Oncology, The University of Texas MD Anderson Cancer Center, Houston, TX 77030, USA. " Department of Nutrition Sciences, University of Alabama at Birmingham, Birmingham, AL 35294, USA. ${ }^{5}$ Division of Population Sciences, Department of Medical Oncology, Dana-Farber Cancer Institute, Harvard Medical School, 375 Longwood Avenue, Boston, MA 02215, USA. ${ }^{6}$ Faculty of Kinesiology, Sport, and Recreation, University of Alberta, Edmonton, Alberta T6G 2H9, Canada.

Received: 13 August 2020 Accepted: 17 November 2020

Published online: 24 November 2020

\section{References}

1. Bradshaw PT, Stevens J, Khankari N, Teitelbaum SL, Neugut Al, Gammon MD. Cardiovascular disease mortality among breast Cancer survivors. Epidemiology. 2016;27(1):6-13.

2. Gernaat SAM, Boer JMA, van den Bongard DHJ, Maas A, van der Pol CC, Bijlsma RM, et al. The risk of cardiovascular disease following breast cancer by Framingham risk score. Breast Cancer Res Treat. 2018;170(1):119-27.

3. Tattersall MC, Gangnon RE, Karmali KN, Keevil JG. Women up, men down: the clinical impact of replacing the Framingham risk score with the Reynolds risk score in the United States population. PLoS One. 2012;7(9): e44347.

4. Ridker PM, Buring JE, Rifai N, Cook NR. Development and validation of improved algorithms for the assessment of global cardiovascular risk in women: the Reynolds risk score. JAMA. 2007;297(6):611-9.

5. Lee K, Tripathy D, Demark-Wahnefried W, Courneya KS, Sami N, Bernstein L, et al. Effect of aerobic and resistance exercise intervention on cardiovascular disease risk in women with early-stage breast Cancer a randomized clinical trial. Jama Oncol. 2019;5(5):710-4.

6. Dieli-Conwright CM, Mortimer JE, Schroeder ET, Courneya K, DemarkWahnefried W, Buchanan TA, et al. Randomized controlled trial to evaluate the effects of combined progressive exercise on metabolic syndrome in breast cancer survivors: rationale, design, and methods. BMC Cancer. 2014; 14.

7. Dieli-Conwright CM, Courneya KS, Demark-Wahnefried W, Sami N, Lee K, Buchanan TA, et al. Effects of aerobic and resistance exercise on metabolic syndrome, Sarcopenic obesity, and circulating biomarkers in overweight or obese survivors of breast Cancer: a randomized controlled trial. J Clin Oncol. 2018:36(9):875-83.

8. Campbell KL, Winters-Stone KM, Wiskemann J, May AM, Schwartz AL, Courneya KS, et al. Exercise guidelines for Cancer survivors: consensus statement from international multidisciplinary roundtable. Med Sci Sport Exer. 2019:51(11):2375-90.

9. Rock CL, Thomson C, Gansler T, Gapstur SM, ML MC, Patel AV, et al. American Cancer Society Guideline for Diet and Physical Activity for cancer prevention. CA Cancer J Clin. 2020;70:245-71.

10. Foroughinia F, Tabibi AA, Javanmardi H, Safari A, Borhani-Haghighi A. Association between high sensitivity C-reactive protein (hs-CRP) levels and the risk of major adverse cardiovascular events (MACE) and/or microembolic signals after carotid angioplasty and stenting. Caspian J Intern Med. 2019;10(4):388-95. 
11. Mongraw-Chaffin M, Bertoni AG, Golden SH, Mathioudakis N, Sears DD, Szklo M, et al. Association of low Fasting Glucose and $\mathrm{HbA1c}$ with cardiovascular disease and mortality: the MESA study. J Endocr Soc. 2019; 3(5):892-901.

12. Appiah D, Nwabuo CC, Owoade DR, Samad J, Ebong I, Winters SJ. Family history of premature myocardial infarction modifies the associations between bilateral oophorectomy and cardiovascular disease mortality in a US national cohort of postmenopausal women. Menopause. 2020;27(6):658-67.

13. Asegaonkar SB, Asegaonkar BN, Takalkar UV, Advani S, Thorat AP. C-reactive protein and breast Cancer: new insights from old molecule. Int J Breast Cancer. 2015;2015:145647.

14. Maskarinec G, Shvetsov YB, Conroy SM, Haiman CA, Setiawan WW, Le Marchand L. Type 2 diabetes as a predictor of survival among breast cancer patients: the multiethnic cohort. Breast Cancer Res Tr. 2019:173(3):637-45.

15. Cook NR, Paynter NP, Eaton CB, Manson JE, Martin LW, Robinson JG, et al. Comparison of the Framingham and Reynolds risk scores for global cardiovascular risk prediction in the multiethnic Women's Health Initiative. Circulation. 2012;125(14):1748-56 S1-11.

\section{Publisher's Note}

Springer Nature remains neutral with regard to jurisdictional claims in published maps and institutional affiliations.

Ready to submit your research? Choose BMC and benefit from:

- fast, convenient online submission

- thorough peer review by experienced researchers in your field

- rapid publication on acceptance

- support for research data, including large and complex data types

- gold Open Access which fosters wider collaboration and increased citations

- maximum visibility for your research: over $100 \mathrm{M}$ website views per year

At $\mathrm{BMC}$, research is always in progress.

Learn more biomedcentral.com/submissions 